\title{
THE EFFECT OF HIGH INTRACRANIAL VENOUS PRESSURE UPON THE CEREBRAL CIRCULATION AND ITS RELATION TO CEREBRAL SYMPTOMS ${ }^{1}$
}

\author{
By EUGENE B. FERRIS, JR. \\ (From the Department of Internal Medicine, Cincinnati General Hospital, and the College of \\ Medicine, University of Cincinnati, Cincinnati)
}

(Received for publication August 16, 1938)

The term "increased intracranial pressure" is often loosely applied to a syndrome consisting of high cerebrospinal fluid pressure, edema of the optic nerve head, often nausea and vomiting, and sometimes unconsciousness and other manifestations of cerebral anoxia. In this syndrome, the high cerebrospinal fluid pressure is generally thought to be an important factor in causing cerebral dysfunction. Our original interest in this subject arose from the fact that many observers have found an increase in the cerebrospinal fluid pressure in venous hypertension of cardiac origin $(1,2,3,4,5,6)$, and several $(2,7,8)$ have postulated that because of the venous stagnation within the brain, or because of the accompanying increase in intracranial pressure, cerebral anoxia results and is responsible for the orthopnea of congestive failure. That such a conclusion may not be warranted is suggested by the fact that cardiac patients, regardless of the height of their venous pressure, rarely, if ever, exhibit the subjective or objective manifestations that are generally associated with " increased intracranial pressure" nor do they have symptoms known to result from cerebral anoxia, such as faintness or unconsciousness $(9,10)$.

To the author's knowledge, studies directly concerning the effect of high peripheral venous pressure upon the circulation through the cranium of man have not been carried out. Because there are many factors, besides venous hypertension, which play a rôle in producing the syndrome of congestive failure, it would seem that a helpful study of this problem could be made on patients who have a high venous pressure in the upper part of the body but who are free from heart failure. We have had the opportunity to observe

1 Read by title at the May 1936 meeting of the American Society for Clinical Investigation, Atlantic City, New Jersey. a number of such patients, suffering from superior vena caval obstruction, of whom few had cardiorespiratory symptoms and none had clinical evidence of "increased intracranial pressure" despite the presence of venous pressures in the upper part of the body as high as $55 \mathrm{~cm} . \mathrm{H}_{2} \mathrm{O}$. A detailed study of five such patients is herewith presented as material which may clarify the relationship between high venous pressure and the cerebral circulation and explain the absence of cerebral manifestations in this type of increased intracranial pressure.

\section{METHOD OF OBSERVATION}

The diagnosis of superior vena caval obstruction was made from the usual clinical findings and by comparative measurement of the pressure in the cubital and femoral veins, a procedure described by Ferris and Wilkins (11). The diagnosis was verified by necropsy in Cases 1 and 3, and by biopsy in Case 5. All studies were made after the patients had rested in bed for several hours and while they were in a horizontal position and in as near a basal state as was possible under the circumstances.

In order to estimate the degree of stagnation of blood within the brain, blood was drawn under oil from the internal jugular vein and internal carotid or femoral artery, using the technique of Myerson, Halloran, and Hirsch (12), and analysis for carbon dioxide content, oxygen content, and oxygen capacity was begun immediately. In one of the cases similar gas studies were made on blood from the cubital and femoral veins as well. In this patient (Case 5) all venous blood samples were obtained without stasis or pain within a period of $3 \mathrm{~min}$ utes. By means of lumbar puncture, the cerebrospinal fluid pressure of 3 cases was determined within a few hours of the other observations. The patients were examined for and questioned about clinical manifestations which might be associated with increased intracranial pressure or cerebral anoxia. Venous pressures were obtained by the direct method of Moritz and Tabora (13), the final reading being referred to a point $5 \mathrm{~cm}$. below the manubrium sterni; blood oxygen content and capacity and carbon dioxide content were determined in duplicate by the manometric method of Van Slyke and Neill as described by Peters and Van Slyke (14). 


\section{RESULTS}

The more important observations which might be related to a high venous pressure in the upper part of the body are tabulated in Table $\mathrm{I}$. The degree of superior vena caval obstruction is indicated by the venous pressure obtained from the cubital vein. The values ranged from 22 to 50 $\mathrm{cm}$. saline, being above $45 \mathrm{~cm}$. in 2 cases. In each case the venous pressure was equal in both arms, and the veins of the head and neck were distended proportionately, indicating that the pressure in all veins draining into the superior cava was equally high. That the cubital venous pressure closely represents the intracranial venous pressure in these cases is shown by the work of Weed and Hughson (15). Their experiments on cats revealed a close correlation between the pressure in the brachial vein and saggital venous sinus. The femoral venous pressure was normal in all but Case 4, where, in addition to superior caval obstruction, there appeared to be some obstruction to the inferior cava as well. The history, and absence of a perceptible superficial venous col- lateral circulation, suggest that the superior caval obstruction had developed rapidly and was of short duration in Cases 1 and 4. It appeared to have developed gradually over a period of months in the others.

Subjective symptoms. The patients experienced very few symptoms which could be related specifically to vena caval obstruction and resulting high venous pressure. Patients 1,4 , and 5 complained of fullness in the head and swelling of the face and neck, while Cases 2 and 3 had no symptoms referable to caval obstruction. All five patients were conscious, completely rational, and denied having headache, visual disturbances, or nausea, and vomiting.

Objective symptoms. All five patients lay flat in bed without discomfort and without orthopnea of necessity or choice. At the time of observation the rate and character of respirations were normal in Cases 1, 2, 3, and 5. In Case 4, the respiratory rate was increased because of pulmonary infection. Case 1 had been free of respiratory symptoms for 36 hours following the

TABLE I

Clinical observations and blood gas studies on 5 patients suffering from superior vena caval obstruction (All studies were carried out with the patients resting in a horizontal position.)

\begin{tabular}{|c|c|c|c|c|c|c|c|c|c|c|c|c|c|c|c|c|c|c|c|}
\hline \multirow[b]{2}{*}{ 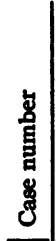 } & \multirow[b]{2}{*}{ 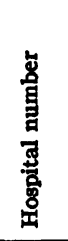 } & \multirow[b]{2}{*}{ 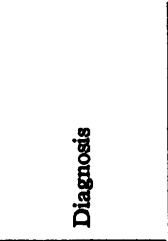 } & \multirow[b]{2}{*}{ 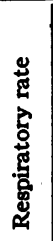 } & \multirow{2}{*}{ 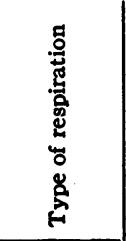 } & \multirow[b]{2}{*}{ 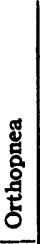 } & \multirow[b]{2}{*}{ 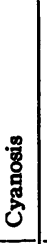 } & \multicolumn{3}{|c|}{$\begin{array}{l}\text { Venous } \\
\text { pressure }\end{array}$} & \multirow[b]{2}{*}{ 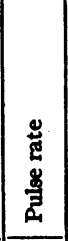 } & \multirow{2}{*}{ 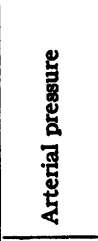 } & \multirow{2}{*}{ 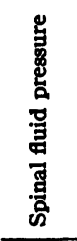 } & \multicolumn{4}{|c|}{ Arterial blood } & \multicolumn{3}{|c|}{$\begin{array}{l}\text { Internal jugular } \\
\text { venous blood }\end{array}$} \\
\hline & & & & & & & 总 & 蛋 & 芯 & & & & 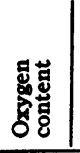 & 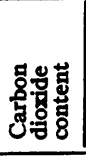 & 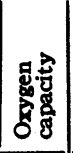 & 总 & 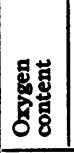 & 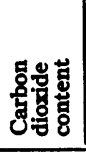 & 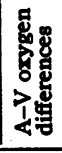 \\
\hline & & & $\begin{array}{c}\text { per } \\
\text { min- } \\
\text { ute }\end{array}$ & & & & & $\underset{\text { sal }}{c n}$ & & $\underset{\substack{\text { min } \\
\text { ute }}}{\text { per }}$ & $\underset{H \boldsymbol{g}}{m m}$ & $\underset{\substack{c \text { com. } \\
\text { spinal } \\
\text { fuid }}}{\text {. }}$ & volun & mes per c & & $\begin{array}{l}\text { per } \\
\text { cent }\end{array}$ & volu & mes per & cent \\
\hline 1 & 64955 & $\begin{array}{l}\text { Aortic } \\
\text { aneurysm }\end{array}$ & 22 & Normal* & 0 & 4 & 2 & 45 & 1 & 80 & $160 / 30$ & & $\begin{array}{l}19.7 \\
\text { (i.c.) } \ddagger\end{array}$ & 33.7 & 22.1 & 89 & 10.5 & 40.1 & 9.2 \\
\hline 2 & 66778 & $\begin{array}{l}\text { Aortic } \\
\text { aneurysm }\end{array}$ & 18 & Normal & 0 & 2 & 1 & 32 & 8 & 90 & $130 / 85$ & 33.4 & $\begin{array}{l}17.8 \\
\text { (i.c.) }\end{array}$ & 42.8 & $|18.3|$ & 97 & 10.2 & 50.2 & 7.6 \\
\hline 3 & 68317 & $\begin{array}{l}\text { Aortic } \\
\text { aneurysm }\end{array}$ & 30 & Shallow & 0 & 1 & 0 & 24 & 5 & 110 & $76 / 48$ & & $\begin{array}{l}13.5 \\
\text { (i.c.) }\end{array}$ & 44.8 & $\mid 14.4$ & 94 & 7.3 & 49.9 & 6.2 \\
\hline 4 & 68959 & $\begin{array}{l}\text { Hodgkin's } \\
\text { disease }\end{array}$ & 20 & Normal & 0 & 2 & 4 & 50 & 20 & 90 & $140 / 80$ & 49.0 & $\begin{array}{l}16.6 \\
\text { (f.) } 8\end{array}$ & 48.4 & 20.0 & 83 & 11.8 & 53.2 & 4.8 \\
\hline 5 & $t$ & $\begin{array}{c}\text { Fibrous } \\
\text { tissue }\end{array}$ & 18 & Normal & 0 & 1 & 1 & 22 & 12 & 72 & $120 / 96$ & 18.0 & $\begin{array}{l}21.9 \\
(f) .\end{array}$ & 44.3 & 22.9 & 95 & 18.1 & & 3.8 \\
\hline
\end{tabular}

* Respirations were normal at the time of these observations; however, the patient had suffered from a severe attack of hyperpnea a few minutes before.

$f$ This patient was observed in the Holmes Hospital through the courtesy of Drs. Russell Speckman and Johnson McGuire.

$¥$ (i.c.) indicates internal carotid artery.

$\S$ (f.) indicates femoral artery. 
onset of the obstruction, but began having brief but severe attacks of hyperpnea a few hours before death, one of which occurred shortly before blood samples were obtained.

Edema was present in the face, neck, and arms in most instances and the amount was roughly proportional to the height of the cubital venous pressure. None of the patients had edema of the lower part of the body. The degree of facial cyanosis evident in the various patients was more marked in those with the higher venous pressures (Table I). It was difficult to estimate in Case 4 because the patient was colored. Examination of the ocular fundi revealed no evidence of edema of the optic disk or retina in any case. The retinal veins, however, were moderately distended in all cases.

Cerebrospinal fluid dynamics. The cerebrospinal fluid pressure was roughly the same as the cubital venous pressure in 3 cases studied. In Case 2, bilateral jugular compression caused a rise in pressure from 33.4 to $35.4 \mathrm{~cm}$., or only $2.0 \mathrm{~cm}$., and abdominal compression a rise to 39.4 or $6.0 \mathrm{~cm}$. ; the pressure was $17.0 \mathrm{~cm}$. after removal of $15 \mathrm{cc}$. of cerebrospinal fluid. In Case 4 , bilateral jugular compression did not affect the cerebrospinal fluid pressure, while maximal abdominal compression raised it from 49.0 to 56.0 or $7.0 \mathrm{~cm}$.; the pressure was $45.0 \mathrm{~cm}$. after removal of $15 \mathrm{cc}$. In Case 5 the pressure was 18.0 $\mathrm{cm}$. Both Cases 2 and 4 developed severe headache subsequent to lumbar puncture, while in Case 5, from which no fluid was removed, this symptom did not develop.

Blood gas studies. The results of determinations of the oxygen and carbon dioxide content and oxygen capacity of arterial and internal jugular venous blood are tabulated in Table $I$.

Except for Case 4, the oxygen saturation of arterial blood was relatively normal. The arteriovenous oxygen difference of internal jugular blood ranged from 3.8 volumes per cent in Case 5 , to 9.2 volumes per cent in Case 1 . A comparison of these figures with those obtained by Lennox and his associates $(16,17)^{2}$ on patients

2 The average arteriovenous oxygen difference obtained by Lennox and his associates in 120 cases was 6.16 volumes per cent. In 50 cases which they tabulated individually the mean arteriovenous oxygen difference was with normal vascular systems indicates no appreciable difference except possibly in Case 1, where the value is at the upper limit of the normal range. This can be explained on the basis of an attack of severe hyperpnea which the patient suffered just before the time of blood sampling and which was probably responsible for the low carbon dioxide values obtained from both arterial and venous blood. Lennox and Gibbs (17) have shown that a fall in the carbon dioxide tension of the blood produced by hyperventilation will cause a marked increase in the arteriovenous oxygen difference.

In Case 5 the oxygen content of internal jugular blood was 1.5 volumes per cent greater than that of antecubital blood and was roughly equal to the oxygen content of blood from the unobstructed femoral vein (Table II).

The carbon dioxide content of the arterial blood was relatively normal except in Case 1. Arteriovenous carbon dioxide differences roughly paralleled the arteriovenous oxygen differences in all instances.

TABLE II

Blood gas studies of samples obtained almost simultaneously (Case 5)

\begin{tabular}{|c|c|c|c|}
\hline Source of blood & $\begin{array}{l}\text { Oxygen } \\
\text { content }\end{array}$ & $\begin{array}{l}\text { Carbon } \\
\text { dioxide } \\
\text { content }\end{array}$ & $\begin{array}{c}\text { A-V } \\
\text { oxygen } \\
\text { difference }\end{array}$ \\
\hline & \multicolumn{3}{|c|}{ volumes per cent } \\
\hline Femoral artery ........... & 21.9 & 44.3 & \\
\hline Internal jugular vein...$\ldots$ & 18.1 & & 3.8 \\
\hline Antecubital vein........... & 16.5 & 51.2 & 5.4 \\
\hline Femoral vein . . . . . . . . . & 18.2 & 48.0 & 3.7 \\
\hline
\end{tabular}

\section{DISCUSSION}

The similarity of the cerebrospinal fluid and venous pressures in 3 of these cases corroborates the findings of Becht (18), Myerson and Loman (19) and others (20), that there is a close relationship between intracranial venous and cerebrospinal fluid pressure. ${ }^{8}$

$\overline{6.65 \pm 0.23}$ volumes per cent with a standard deviation of $2.45 \pm 0.16$.

3 In connection with the effect of venous upon cerebrospinal fluid pressure, it is of interest that a patient with inferior vena caval obstruction had a normal cerebrospinal fluid pressure and normal responses to bilateral jugular and abdominal compression. The obstruction was proved to be between the right renal and hepatic veins. The venous pressures were: antecubital $2.0 \mathrm{~cm} . \mathrm{H}_{2} \mathrm{O}$, 
The results indicate that in all cases the difference between the oxygen content of arterial and internal jugular venous blood is within normal limits. Calhoun, Cullen, Harrison, Wilkins, and Tims (21) also obtained normal arteriovenous oxygen differences from arterial and internal jugular venous blood in 3 of 4 patients suffering from orthopnea of cardiac origin, but made no note of the venous pressures in their cases. Their fourth case had a value of 10.53 volumes per cent, but like Case 1 of this series the patient had a low carbon dioxide tension in his blood as the result of hyperventilation. Since there is no reason to suspect that the patients herein reported had an abnormally low tissue metabolism, the arteriovenous oxygen differences obtained clearly indicate that the blood flow through the cranium was relatively normal in spite of the venous hypertension. There is also considerable clinical evidence which suggests that the blood flow through the cranium was normal; namely, no symptoms indicative of cerebral anoxia, such as weakness, dizziness or faintness, were present. The normal blood flow is in marked contrast to the venous stasis which appeared to be present in the superficial veins, as evidenced by facial cyanosis and edema. The fact that in Case 5 the oxygen content of cubital venous blood was 1.5 volumes per cent less than that in the femoral and internal jugular veins, is further indication for the existence of more marked stasis in the upper extremity than in the head. This latter observation seems significant because Lennox $(16,22)$ has shown that normally the oxygen content of blood from the internal jugular vein is less than that of blood obtained simultaneously from peripheral veins.

The compensatory mechanism responsible for the normal cerebral blood flow is not clarified by this study. Among others, Cushing (23) and Becht (18) have shown that great increases in cerebrospinal fluid pressure are accompanied by an increase in arterial pressure, but it is thought that this mechanism is not brought into action until the intracranial pressure approaches that of arterial blood. However, Becht's data show that elevations of cerebrospinal pressure within the

femoral $22 \mathrm{~cm}$. Cerebrospinal fluid pressures were: initial, $12 \mathrm{~cm}$. spinal fluid; during jugular compression, $18 \mathrm{~cm}$; during abdominal compression, $22 \mathrm{~cm}$. limits encountered in the cases herein reported may often produce a definite increase in systemic arterial pressure. In recent unpublished experiments, Williams and Lennox (24) have shown that the cerebral blood flow is normal in patients having increased intracranial pressure. They suggest that the compensatory mechanism may result from the vasodilating action of $\mathrm{CO}_{2}$ on the cerebral vessels. Conclusive proof as to the importance of either of these mechanisms is lacking because the blood pressure change necessary to compensate for the increased cerebrospinal fluid and venous pressures would be so small that the recorded arterial pressures would not be altered significantly.

It is of considerable interest that patients may have venous and cerebrospinal fluid pressures as high as $500 \mathrm{~mm} . \mathrm{H}_{2} \mathrm{O}$ and not only maintain a normal rate of blood flow through the brain, but also be free of any clinical manifestations generally associated with increased intracranial pressure. Friedfeld and Fishberg (3) have also noted the lack of cerebral symptoms in a patient with congestive failure whose cerebrospinal fluid pressure was $450 \mathrm{~mm}$. spinal fluid, and Weigeldt (1) has commented on the absence of papilledema in a case of superior caval obstruction. The lack of abnormal cerebral manifestations and the absence of any edema of the optic disc suggests that, in contrast to the superficial tissues, there is no significant alteration in fluid exchange between the blood and tissue of the brain in these cases.

The explanation of the intracranial dynamics in venous hypertension of this type probably depends upon the fact that the craniovertebral contents are enclosed in a container which is almost rigid, with the exception of the emerging vascular tree (25). Except for the venous and capillary systems, the craniovertebral cavity is filled with cerebrospinal fluid and tissue, both of which are non-compressible, and with arterial blood which will decrease in volume only under relatively high external pressure or with marked diminution in arterial pressure. The fact that, in man, bilateral jugular compression and release results in a prompt rise and return to normal of the cerebrospinal fluid pressure, suggests that the high pressure in these cases is not owing to an increase in fluid volume; and the work of Becht 
(18) and of Bedford (20) on animals supports this belief. Increased pressure distributed uniformly throughout the intracranial veins and capillaries should therefore be transmitted completely to other intracranial systems, because, owing to the inability of the surrounding contents to change in volume, the vessel walls cannot distend sufficiently to absorb a significant amount of pressure. The close similarity of the cerebrospinal fluid and peripheral venous pressures in the three observed cases is consistent with this concept. Experiments in animals, adequately reviewed by Bedford, indicate that in general when the veins are occluded, the cerebrospinal fluid pressure does not quite reach the venous pressure; and observations in man of the cerebrospinal fluid pressure in venous hypertension of cardiac origin show considerable discrepancy between the two pressures. Such observations are not necessarily inconsistent with the above explanation because in the animal studies occlusion of all veins draining the cranium was not effected as it was in these cases, and in man, marked alteration in cerebrospinal fluid pressure will result from the respiratory abnormalities $(26,27)$ which occur so regularly in cardiac failure. If one accepts the hypothesis that meningeal tension, caused either by edema, displacement, or venous dilatation, will produce headache $(28,29)$, limitation of volume changes within the cranium by the factors described above would account for the absence of this symptom and its appearance after removal of cerebrospinal fluid.

The absence of orthopnea in these cases indicates that high venous pressure alone cannot cause orthopnea. Blumgart and his associates $(7,8)$ suggest that venous hypertension results in venous stasis within the brain and that the resulting stagnation anoxemia, which would be more marked in the horizontal position, accounts for the orthopnea of congestive heart failure. Harrison (2), too, explains orthopnea on the basis of anoxia but postulates another mechanism, namely, that the increased cerebrospinal fluid pressure which results from the venous hypertension, so obstructs the cerebral blood vessels that anoxia ensues. Since it appears from the studies herein reported that venous hypertension of extreme degree does not necessarily result in venous stagnation within the cranium, or in diminution of the rate of cerebral blood flow, such hypotheses require further proof of the existence of cerebral anoxia in orthopneic cardiac patients. The studies of Calhoun et al. (21), showed that in orthopneic patients the oxygen difference between arterial and internal jugular blood was normal and did not vary significantly with changes in position. Robb and Weiss (30) also found that many patients with orthopnea of cardiac origin had normal venous pressures. These observations throw additional doubt upon the importance of venous hypertension as a cause for cardiac orthopnea.

\section{SUMMARY AND CONCLUSIONS}

1. Observations on 5 patients with superior vena caval obstruction are presented.

2. In 3 patients tested, the elevation in venous pressure was accompanied by a similar increase in the cerebrospinal fluid pressure.

3. In spite of high venous pressure in the upper part of the body, and evidence of venous stasis in the face and arms, the rate of blood flow through the cranium was normal. This was evidenced by: (a) normal arteriovenous oxygen differences between arterial and internal jugular venous blood; and $(b)$ the absence of any manifestations suggesting cerebral anoxia.

4. In contrast to the presence of edema in the face and arms, there was no clinical evidence of cerebral edema.

5. It is suggested that in the presence of high intracranial venous pressure the rigid covering of the craniovertebral cavity is the important factor in preventing sufficient venous distention and alteration in fluid exchange between the blood and tissues of the brain to cause symptoms.

6. These observations do not support the hypothesis that venous hypertension, through its effect on the cerebral blood flow, is an important cause for orthopnea.

The author is indebted to Miss Rose Shore for technical assistance.

\section{BIBLIOGRAPHY}

1. Weigeldt, W., Studien zur Physiologie und Pathologie des Liquor cerebrospinalis. Jena, G. Fischer, 1923.

2. Harrison, W. G., Jr., Cerebrospinal fluid pressure and venous pressure in cardiac failure. The effect of spinal drainage in the treatment of cardiac decompensation. Arch. Int. Med., 1934, 53, 782. 
3. Friedfeld, L., and Fishberg, A. M., The relation of the cerebrospinal and venous pressures in heart failure. J. Clin. Invest., 1934, 13, 495.

4. Merritt, H. H., and Fremont-Smith, F., The Cerebrospinal Fluid. W. B. Saunders Co., Philadelphia, 1937.

5. Robertson, H. F., and Fetter, F., The effect of venesection on arterial, spinal fluid, and venous pressures with especial reference to failure of the left and right heart. J. Clin. Invest., 1935, 14, 305.

6. Greene, J. A., Paul, W. D., and Feller, A. E., The action of theophylline with ethylenediamine on intrathecal and venous pressures in cardiac failure and on bronchial obstruction in cardiac failure and in bronchial asthma. J. A. M. A., 1937, 109, 1712.

7. Ernstene, A. C., and Blumgart, H. L., Orthopnea. Its relation to the increased venous pressure of myocardial failure. Arch. Int. Med., 1930, 45, 593.

8. Altschule, M. D., and Blumgart, H. L., The circulatory dynamics in tricuspid stenosis. Their significance in the pathogenesis of edema and orthopnea. Am. Heart J., 1937, 13, 589.

9. Weiss, S., and Baker, J. P., The carotid sinus reflex in health and disease. Its rôle in the causation of fainting and convulsions. Medicine, 1933, 12, 297.

10. Ferris, E. B., Jr., Capps, R. B., and Weiss, S., Carotid sinus syncope and its bearing on the mechanism of the unconscious state and convulsions. A study of 32 additional cases. Medicine, 1935, 14, 377.

11. Ferris, E. B., Jr., and Wilkins, R. W., The clinical value of comparative measurements of the pressure in the femoral and cubital veins. Am. Heart J., 1937, 13, 431.

12. Myerson, A., Halloran, R. D., and Hirsch, H. L., Technique for obtaining blood from the internal jugular vein and internal carotid artery. Arch. Neurol. and Psychiat., 1927, 17, 807.

13. Moritz, F., and von Tabora, D., Uber eine Methode, beim Menschen den Druck in oberflächlichen Venen exakt $\mathrm{zu}$ bestimmen. Deutsches Arch. f. klin. Med., 1910, 98, 475.

14. Peters, J. P., and Van Slyke, D. D., Quantitative Clinical Chemistry. Vol. II. Methods. Williams and Wilkins Co., Baltimore, 1932.

15. Weed, L. H., and Hughson, W., Intracranial venous pressure and cerebrospinal fluid pressure as affected by the intravenous injection of solutions of various concentrations. Am. J. Physiol., 1921-22, 58, 101.

16. Lennox, W. G., The cerebral circulation. XIV. The respiratory quotient of the brain and of the extremities in man. Arch. Neurol. and Phychiat., 1931, 26, 719.

17. Lennox, W. G., and Gibbs, E. L., The blood flow in the brain and the leg of man, and the changes in- duced by alteration of blood gases. J. Clin. Invest., 1932, 11, 1155.

18. Becht, F. C., Studies on the cerebrospinal fluid. Am. J. Physiol., 1920, 51, 1.

19. Myerson, A., and Loman, J., Internal jugular venous pressure in man. Its relationship to cerebrospinal fluid and carotid arterial pressures. Arch. Neurol. and Psychiat., 1932, 27, 836.

20. Bedford, T. H. B., The effect of increased intracranial venous pressure on the pressure of the cerebrospinal fluid. Brain, 1935, 58, 427.

21. Calhoun, J. A., Cullen, G. E., Harrison, T. R., Wilkins, W. L., and Tims, M. M., Studies in congestive heart failure. XIV. Orthopnea: Its relation to ventilation, vital capacity, oxygen saturation and acid-base condition of arterial and jugular blood. J. Clin. Invest., 1931, 10, 833.

22. Lennox, W. G., The oxygen and carbon dioxide content of blood from the internal jugular and other veins. Arch. Int. Med., 1930, 46, 630.

23. Cushing, $H$., Concerning a definite regulatory mechanism of the vasomotor centre which controls blood pressure during cerebral compression. Bull. Johns Hopkins Hosp., 1901, 12, 290.

24. Williams, D. J., and Lennox, W. G., The cerebral blood flow in arterial hypertension, arteriosclerosis and high intracranial pressure. (To be published).

25. Weed, L. H., and Hughson, W., The cerebrospinal fluid in relation to the bony encasement of the central nervous system as a rigid container. Am. J. Physiol., 1921-22, 58, 85.

26. Wolff, H. G., and Lennox, W. G., Cerebral circulation. XII. The effect on pial vessels of variations in the oxygen and carbon dioxide content of the blood. Arch. Neurol. and Psychiat., 1930, 23, 1097.

27. Cobb, S., and Fremont-Smith, F., The cerebral circulation. XVI. Changes in the human retinal circulation and in the pressure of the cerebrospinal. fluid during inhalation of a mixture of carbon dioxide and oxygen. Arch. Neurol. and Psychiat., 1931, 26, 731.

28. Pickering, G. W., Observations on the mechanism of headache produced by histamine. Clin. Sc., 1933$34,1,77$.

29. Penfield, W., A contribution to the mechanism of intracranial pain. Assoc. Research Nerv. and Ment. Dis. (Proc.), 1935, 15, 399.

30. Robb, G. P., and Weiss, S., The velocity of pulmonary and peripheral venous blood flow and related aspects of the circulation in cardiovascular disease. Their relation to clinical types of circulatory failure. Am. Heart J., 1934, 9, 742. 